\title{
Long-term trends in the ionospheric F2 region with different solar activity indices
}

\author{
J. Mielich and J. Bremer \\ Leibniz-Institute of Atmospheric Physics at the Rostock University, Schloss-Str. 6, 18225 Kühlungsborn, Germany \\ Correspondence to: J. Bremer (bremer@iap-kborn.de)
}

Received: 3 September 2012 - Revised: 17 January 2013 - Accepted: 22 January 2013 - Published: 19 February 2013

\begin{abstract}
A new comprehensive data collection by Damboldt and Suessmann (2012a) with monthly foF2 and $\mathrm{M}(3000) \mathrm{F} 2$ median values is an excellent basis for the derivation of long-term trends in the ionospheric F2 region. Ionospheric trends have been derived only for stations with data series of at least 22 years ( 124 stations with $f o \mathrm{~F} 2$ data and 113 stations with M(3000)F2 data) using a twofold regression analysis depending on solar and geomagnetic activity.

Three main results have been derived:

Firstly, it could be shown that the solar $10.7 \mathrm{~cm}$ radio flux F10.7 is a better index for the description of the solar activity than the relative solar sunspot number $R$ as well as the solar EUV proxy E10.7.

Secondly, the global mean $f o \mathrm{~F} 2$ and $h m \mathrm{~F} 2$ trends derived for the interval between 1948 and 2006 are in surprisingly good agreement with model calculations of an increasing atmospheric greenhouse effect (Rishbeth and Roble, 1992).

Thirdly, during the years 2007 until 2009, the $h m F 2$ values and to a smaller amount the $f o \mathrm{~F} 2$ values strongly decrease. The reason for this effect is a reduction of the thermospheric density and ionization due to a markedly reduced solar EUV irradiation and extremely small geomagnetic activity during the solar cycle 23/24 minimum.
\end{abstract}

Keywords. Ionosphere (Wave propagation)

\section{Introduction}

Long-term trends in the upper atmosphere/ionosphere have been initiated by model calculations of Roble and Dickinson (1989), Rishbeth (1990), and Rishbeth and Roble (1992). They predicted a lowering of the $\mathrm{F} 2$ peak height $h m \mathrm{~F} 2$ by -10 to $-20 \mathrm{~km}$ and a reduction of the critical frequency $f o \mathrm{~F} 2$ by about -0.2 to $-0.5 \mathrm{MHz}$ for a doubling of the greenhouse gas $\mathrm{CO}_{2}$ in the Earth's atmosphere. These model predictions can be tested by long-term ionosonde observations which are available at many stations around the world partly available since about 1940. A lot of investigations have been done in the past with data of single stations (e.g. Bremer, 1992; Hall and Cannon, 2002) as well as analyses with different stations (e.g. Bremer, 2004; Ulich, 2000). Additional references of such analyses can be found in recent papers by Qian et al. (2011) and Bremer et al. (2012).

An important point in the ionospheric trend analyses is the elimination of the solar and geomagnetic activity-induced parts. Different methods have been used such as different regression analyses (Bremer, 1992; Alfonsi et al., 2002; de Adler et al., 2002), a statistical inversion method (Ulich, 2000), a neural network model (Yue et al., 2006), and two different methods for elimination of geomagnetic long-term effects (Mikhailov et al., 2002; Danilov, 2002, 2003).

In most of the published ionospheric trend analyses, the solar sunspot number $R$ has been used as proxy of the solar EUV radiation. However, there are also other indices such as the solar $10.7 \mathrm{~cm}$ radio flux or the E10.7 index developed by Tobiska et al. (2000). Whereas Bremer (2001) did not detect essential differences in the trends derived with different solar activity indices for one station, Jarvis et al. (1998) and Ulich et al. (2006) found, however, slightly less noisy results if F10.7 was used instead of $R$.

As the influence of the solar activity causes marked variations in different ionospheric key parameters $f o \mathrm{~F} 2$ and $h m \mathrm{~F} 2$, it is necessary to use the optimum solar activity index to derive the small ionospheric long-term trends. In the present paper, trend analyses are carried out for more than 100 worldwide distributed ionosonde stations using their $f_{o} \mathrm{~F} 2$ and $h m \mathrm{~F} 2$ data series collected in a new databank with monthly median values of these parameters (Damboldt and 


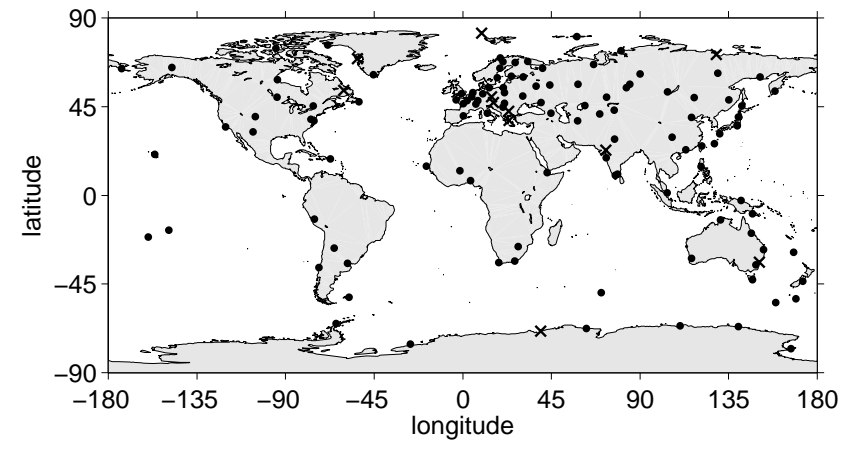

Fig. 1. Ionosonde stations with observations of at least 22 years from the databank of Damboldt and Suessmann (2012a). Dots indicate stations with $f o \mathrm{~F} 2$ and $\mathrm{M}(3000) \mathrm{F} 2$ data, and crosses indicate stations with $f o \mathrm{~F} 2$ data only.

Suessmann, 2012a). These analyses have been made for the above-mentioned different solar activity indices, the solar sunspot number $R$, the solar $10.7 \mathrm{~cm}$ radio flux F10.7, and the solar EUV proxy E10.7 to find the most appropriate solar index for trend analyses. This is the first main topic of this paper. The second main point is the derivation of mean global trends of $f o \mathrm{~F} 2$ and $h m \mathrm{~F} 2$ and their comparison with model predictions of an increasing atmospheric greenhouse effect. The third topic is directed to the investigation of the unusual behaviour of the ionospheric parameters $f o \mathrm{~F} 2$ and $h m \mathrm{~F} 2$ during the solar cycle 23/24 minimum.

Some data of the databank of Damboldt and Suessmann (2012a) have been used for the first time by Bremer et al. (2012). Here trend results have been compared from analyses with two different methods for a limited data set (37 stations). In these analyses the solar sunspot number $R$ has been used as solar activity index. From these results mean global trends have been estimated, and the variation of $h m \mathrm{~F} 2$ during the low solar cycle 23/24 minimum was analysed. Some of these investigations are continued in this paper, however, on an essentially larger data basis and with the solar F10.7 index instead of the solar sunspot number $R$. The markedly enhanced data volume (113 stations with $h m \mathrm{~F} 2$ and 124 stations with $f_{o} \mathrm{~F} 2$ values) will increase the significance level of the derived mean trends. The investigation of the ionospheric variation during the solar cycle 23/24 minimum is extended, including now for the first time in addition to $h m \mathrm{~F} 2$ also the variation of $f o \mathrm{~F} 2$.

In Sect. 2 of this paper, the trend analysis method is shortly described together with some details of the used ionospheric database and the different solar indices. In Sect. 3 the trend results are presented followed by a discussion of the derived trends in Sect. 4. Conclusions with the main results are given in Sect. 5.

\section{Analysis method and experimental database}

\subsection{Method of trend analysis}

For a detection of ionospheric trends, it is necessary to remove the influence of the solar (and the geomagnetic) activity. As introduced by Bremer (1992), this part can be approximated by a twofold regression equation:

$X_{\mathrm{th}}=A+B \cdot \mathrm{SA}+C \cdot \mathrm{Ap}$.

Here $X$ is the ionospheric parameter $f o \mathrm{~F} 2$ or $h m \mathrm{~F} 2$, SA the solar activity parameter $R, \mathrm{~F} 10.7$, or E10.7, and Ap is the global geomagnetic activity index. Then the differences between the observed ionospheric parameter $X_{\exp }$ and the corresponding model value $X_{\text {th }}$ are calculated according to

$\Delta X=X_{\exp }-X_{\text {th }}$

For each hour and each month, such data series are calculated (i.e. $12 \times 24$ data series). These data series can be analysed separately, but often yearly $\Delta X$ mean values are used (as in this paper) to derive linear trends according to

$\Delta X=D+E \cdot$ year.

Here $E$ is the trend parameter in $\mathrm{km} \mathrm{year}^{-1}$ for $h m \mathrm{~F} 2$ data and in $\mathrm{MHz}_{\text {year }}{ }^{-1}$ for $f o \mathrm{~F} 2$ values.

\subsection{Ionospheric database}

The trend analyses presented in this paper are based on the data collection of Damboldt and Suessmann (2012a) with monthly median values of $f o \mathrm{~F} 2$ and $\mathrm{M}(3000) \mathrm{F} 2$ from more than 200 different stations ( $f o \mathrm{~F} 2: 259$ stations, $\mathrm{M}(3000) \mathrm{F} 2$ : 240 stations). The data series are available from 1941 for foF 2 and from 1942 for M(3000)F2 and finish in 2009. However, the data length at most stations is markedly shorter. We selected only stations with data intervals of at least 22 years corresponding to about two solar cycles. As the F10.7 data are only available since 14 February 1947, we used in the trend analyses only data since the year 1948. With this limitation we analysed 124 stations with $f o \mathrm{~F} 2$ values and 113 stations with M(3000)F2 data. In Fig. 1 the global distribution of these stations is shown for those that have been used in this paper. The stations with $f o \mathrm{~F} 2$ and $\mathrm{M}(3000) \mathrm{F} 2$ data are marked by dots; the stations with $f_{o} \mathrm{~F} 2$ values only are denoted by crosses. As to be seen, the available stations are predominately in the Northern Hemisphere with a strong clustering in Europe.

It is difficult for a foreign user to check the quality of the data in the data collection of Damboldt and Suessmann (2012a). If we, however, found some discontinuities in individual data series, these series have been removed from the trend analyses. Examples of such discontinuities have been found in previous investigations (Bremer, 2001, 2004). 


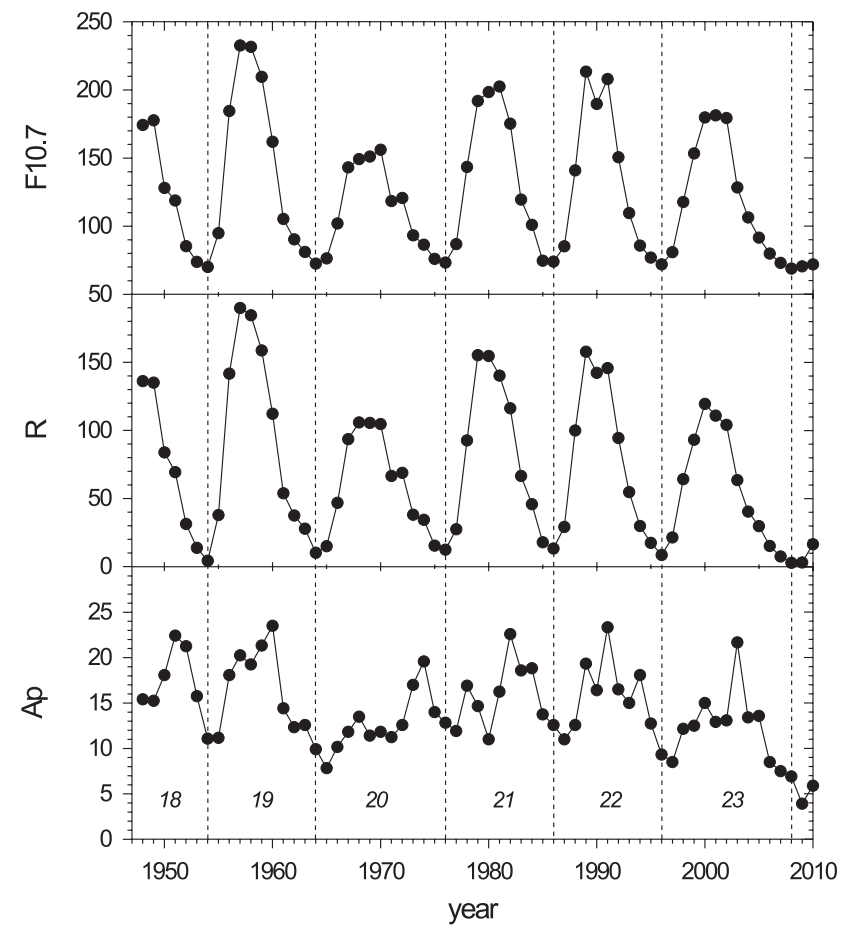

Fig. 2. Long-term variation of solar $10.7 \mathrm{~cm}$ radio flux F10.7, solar sunspot number $R$, and geomagnetic Ap value. The vertical dashed lines mark the boundaries of the different solar cycles.

In the trend analyses we did not use the $\mathrm{M}(3000) \mathrm{F} 2$ data but $h m \mathrm{~F} 2$ values derived from the $\mathrm{M}(3000) \mathrm{F} 2$ values according to the well-known formula of Shimazaki (1955):

$h m \mathrm{~F} 2=1490 / \mathrm{M}(3000) \mathrm{F} 2-176$.

There are of course more complicated and even more accurate formulas for the derivation of the F2 peak height using additional information about the underlying ionization (e.g. Bilitza et al., 1979). But such data are not available in the used databank of Damboldt and Suessmann (2012a). Therefore, we had to use the simple Eq. (4).

\subsection{Solar activity indices}

In Fig. 2 the yearly variations of the solar activity indices F10.7 and $R$ are presented together with the variation of the geomagnetic Ap index for the time interval between 1948 and 2010 thus consisting of nearly 6 solar cycles (mainly cycles $18-23$ ). Here the variation of $R$ and F10.7 is very similar, confirmed by the highly significant correlation between both yearly mean data sets (correlation coefficient $r=0.99$ ).

If we, however, consider the dependence between $R$ and F10.7 separately for the time interval from 1948 to 2000 and for the interval from 2001 to 2009, then we can observe marked differences as shown in Fig. 3. Here the yearly $R$ values from 2001 to 2009 (dots connected with a polynomial fit of second order) are markedly smaller than the correspond-

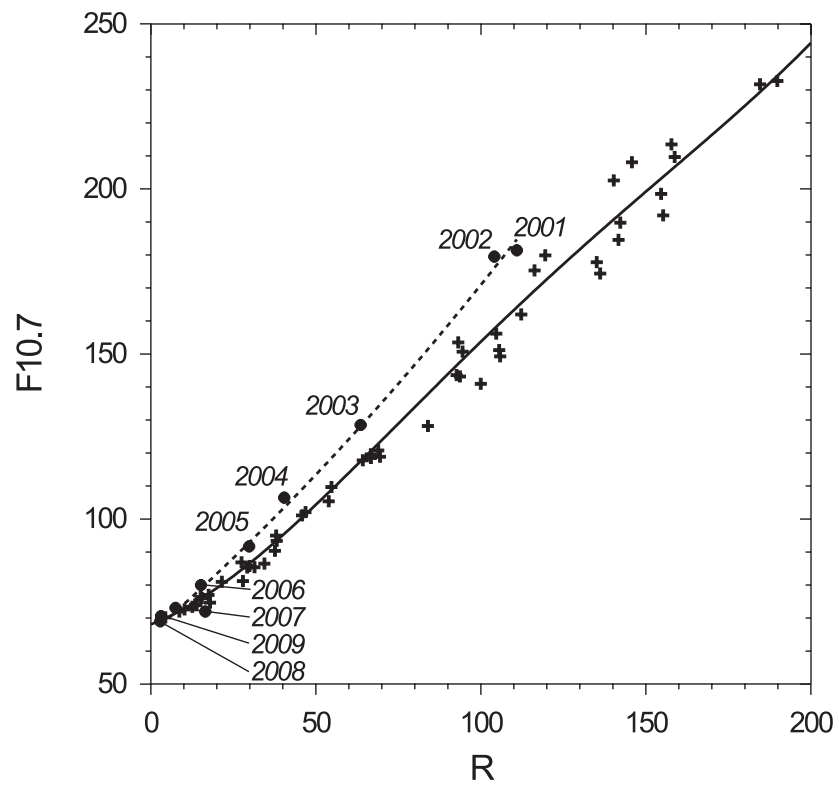

Fig. 3. Relation between yearly mean values of the solar $10.7 \mathrm{~cm}$ radio flux F10.7 and the solar sunspot number $R$. The values from 1948 until 2000 are marked by crosses and are adapted by a polynomial fit of fourth order (continuous curve); the values from 2001 until 2009 are marked by full dots and are adapted by a polynomial fit of second order (dashed curve).

ing data of the interval from 1948 to 2000 (crosses connected with a polynomial fit of forth order). These smaller $R$ values during 2001 to 2009 are strongly confirmed by Floyd et al. (2005) and Lukianova and Mursula (2011). These authors detected, in comparisons between the solar sunspot number $R$ and different EUV indices (F10.7, MGII core-to-wing ratio, HeI 1083 equivalent width), marked differences during the period from 2001 until 2008 thus demonstrating that the $R$ values underestimate the solar EUV radiation during this period.

In spite of the strong correlation between the yearly $R$ and F10.7 values mentioned above in connection with Fig. 2, some differences may occur between these solar indices as demonstrated in Fig. 3. Therefore, it is an essential point of this paper to compare ionospheric trends derived with $R$ or F10.7 indices. Additionally, the solar EUV proxy E10.7 (Tobiska et al., 2000) has been tested in selected trend analyses.

\section{Results of ionospheric trends}

\subsection{Comparison of trends with different solar indices}

In the first two of three subsections, trends in $h m \mathrm{~F} 2$ - and $f o \mathrm{~F} 2$ data series are separately derived by use of the solar sunspot number $R$ as well as the solar $10.7 \mathrm{~cm}$ radio flux F10.7. In a third subsection we investigated if the solar EUV proxy 

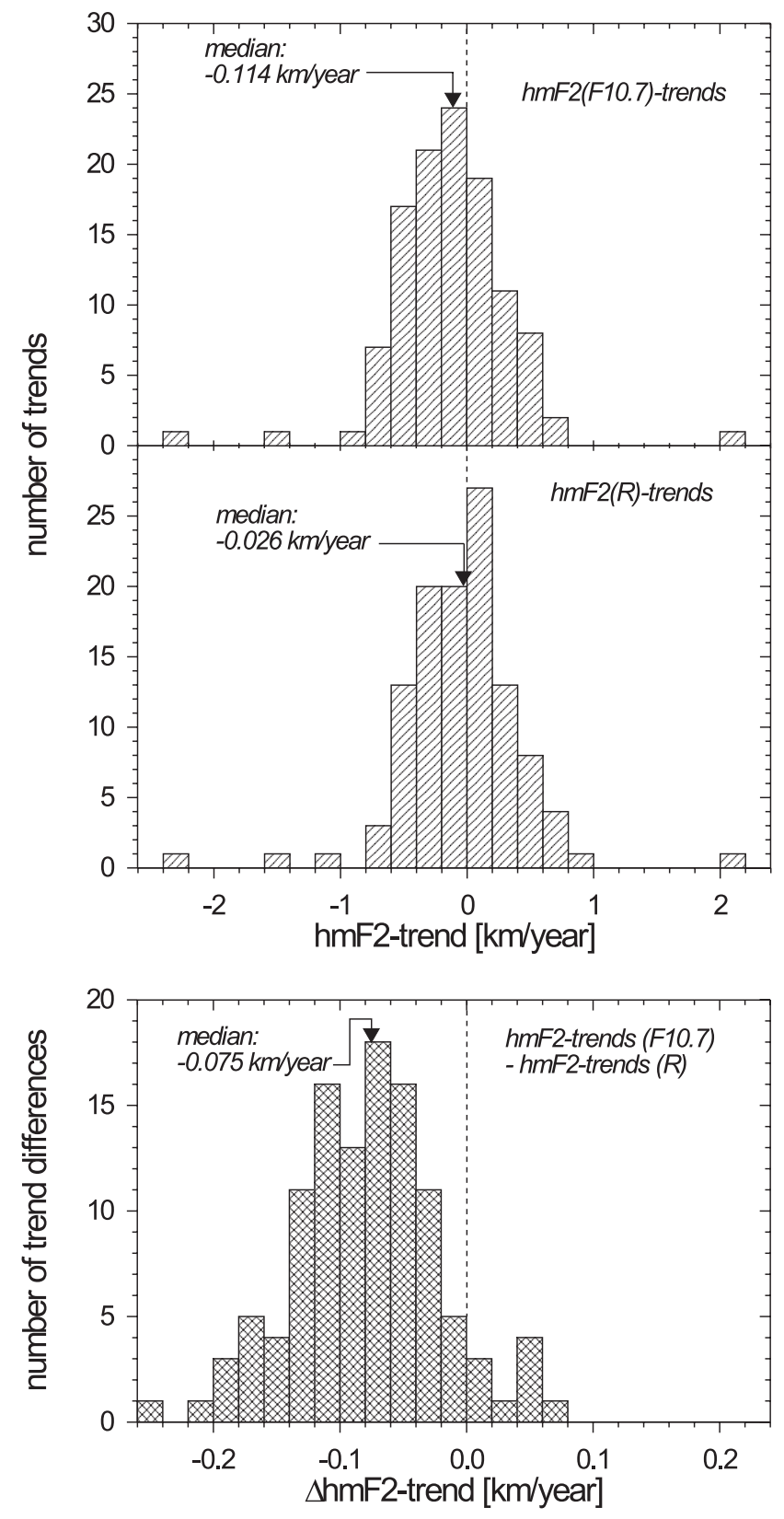

Fig. 4. Histograms of $h m \mathrm{~F} 2$ trends by use of $\mathrm{F} 10.7$ or $R$ data in the trend analyses (upper part) as well as a histogram of the differences of both $h m \mathrm{~F} 2$ trends (lower part). The corresponding median values are marked by arrows.

E10.7 (Tobiska et al., 2000) can also successfully be used in such trend analyses.

\subsubsection{Trends in $h m \mathrm{~F} 2$ data with solar indices $R$ and F10.7}

For all 113 stations with $h m \mathrm{~F} 2$ data series of at least 22-yr duration during the time interval from 1948 until 2009, trends have been estimated by use of the two solar activity indices

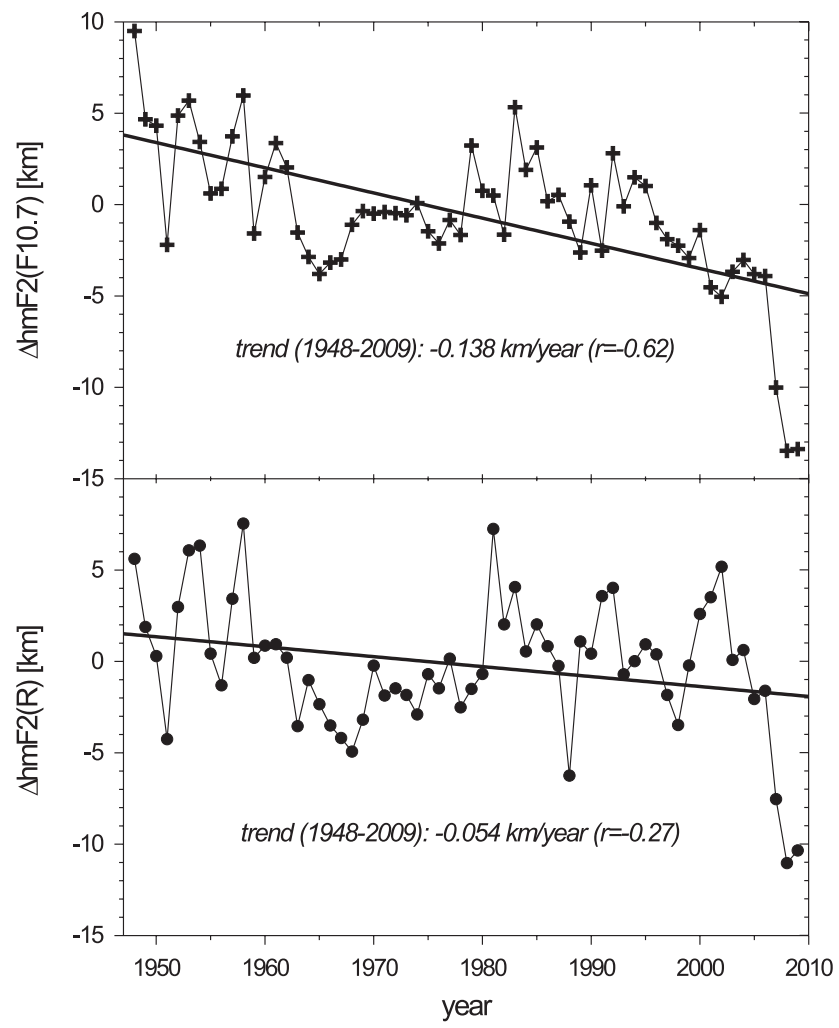

Fig. 5. Global mean $h m \mathrm{~F} 2$ trends by use of F10.7 (upper part) or $R$ data (lower part) in the trend analyses.

$R$ and F10.7. In the upper part of Fig. 4, two histograms are presented for the trends derived with these two indices. The corresponding median values are marked by arrows. In the lower part of Fig. 4, an additional histogram is presented for the trend differences: $h m \mathrm{~F} 2$ trend( $\mathrm{F} 10.7)-h m \mathrm{~F} 2$ trend $(R)$. As can be seen from these histograms together with the corresponding median values, the $h m \mathrm{~F} 2$ trends(F10.7) are generally smaller (more strongly negative) than the corresponding $h m \mathrm{~F} 2$ trends $(R)$.

From all 113 individual $h m \mathrm{~F} 2$ trends, mean global trends are estimated for both solar indices. These global mean trends are presented in Fig. 5, in the upper part mean trend using F10.7 values, in the lower part mean trends using $R$ values. As to be expected from the results presented in Fig. 4, also here the global $h m \mathrm{~F} 2$ trend(F10.7) is more strongly negative than the global $h m \mathrm{~F} 2$ trend $(R)$. The mentioned mean $h m \mathrm{~F} 2$ trend values are summarized in the upper part of Table 1. For the global trends in this table, also the error values $\varepsilon_{\mathrm{t}}$ deduced from the Student's $t$ test are added via the following formula:

$\varepsilon_{\mathrm{t}}=\frac{t_{95}(N-2)}{\sqrt{N-2}} \sqrt{\left(\frac{\mathrm{STD}_{\Delta x}^{2}}{\mathrm{STD}_{\text {year }}^{2}}-E_{\Delta x(\text { year })}\right)}$

with $\Delta X=\Delta h m \mathrm{~F} 2$ in this subsection and $\Delta X=\Delta f o \mathrm{~F} 2$ in the following subsection, the number of years $N$, the 
Table 1. Estimated mean trend values of $h m \mathrm{~F} 2$ and $f o \mathrm{~F} 2$ with error bars using two different solar activity indices in the trend analyses of 113 stations with $h m \mathrm{~F} 2$ and 124 stations with foF2 data for the time interval from 1948 until 2009.

\begin{tabular}{llll}
\hline Parameter & Trend & Trend $(R)$ & Trend $(\mathrm{F} 10.7)$ \\
\hline \multirow{2}{*}{$h m \mathrm{~F} 2$} & Global trend & -0.054 & -0.138 \\
& & $\pm 0.050 \mathrm{~km} \mathrm{year}^{-1}$ & $\pm 0.044 \mathrm{~km} \mathrm{year}^{-1}$ \\
& Individual trends (mean) & -0.042 & -0.121 \\
& & $\pm 0.088 \mathrm{~km} \mathrm{year}^{-1}$ & $\pm 0.088 \mathrm{~km} \mathrm{year}^{-1}$ \\
& Individual trends (median) & $-0.026 \mathrm{~km} \mathrm{year}^{-1}$ & $-0.114 \mathrm{~km} \mathrm{year}^{-1}$ \\
\hline \multirow{3}{*}{ foF2 } & Global trend & 0.0007 & -0.0038 \\
& & $\pm 0.0032 \mathrm{MHz} \mathrm{year}^{-1}$ & $\pm 0.0029 \mathrm{MHz} \mathrm{year}^{-1}$ \\
& Individual trends (mean) & 0.0004 & -0.0042 \\
& & $\pm 0.0016 \mathrm{MHz} \mathrm{year}^{-1}$ & $\pm 0.0016 \mathrm{MHz} \mathrm{year}^{-1}$ \\
& Individual trends (median) & $0.0014 \mathrm{MHz} \mathrm{year}^{-1}$ & $-0.0030 \mathrm{MHz} \mathrm{year}^{-1}$ \\
\hline
\end{tabular}

standard deviation $\mathrm{STD}_{\Delta X}$ and $\mathrm{STD}_{\text {year }}$, and the $t$ value for $95 \%$ reliability level $t_{95}(N-2)$ (Taubenheim, 1969). In the upper part of Table 1 , also the median values of the individual trends (as shown in Fig. 4) are included as well as the mean values of the individual trends together with their error values derived by the following formula:

$\varepsilon_{\mathrm{m}}=t_{95}(N-1) \mathrm{STD} / \sqrt{N}$

with the number of stations $N$, the standard deviation of the individual trends STD, and the $t$ value for $95 \%$ reliability $t_{95}(N-1)$ (Taubenheim, 1969).

As partly remarked above (see Figs. 4 and 5), all three mean $h m \mathrm{~F} 2$ trend parameters are more strongly negative if the F10.7 values have been used in the trend analyses. Also the significance levels are higher for these trends than those of the corresponding $h m \mathrm{~F} 2(R)$ trends.

\subsubsection{Trends in $f o F 2$ data with solar indices $R$ and F10.7}

Similar trend analyses as for $h m \mathrm{~F} 2$ data series presented in Sect. 3.1.1 have also been carried out for all available 124 ionosonde stations with long-term $f o \mathrm{~F} 2$ observations. In the upper part of Fig. 6, histograms of the derived $f o \mathrm{~F} 2$ trends of the individual stations are separately presented for analyses with F10.7 or $R$. In the lower part of Fig. 6, the trend differences, $f o \mathrm{~F} 2$ trend(F10.7) $-f o \mathrm{~F} 2$ trend $(R)$, are shown. Nearly all of these differences are negative. In each case the corresponding median value is marked by an arrow. Whereas the median of the $f o \mathrm{~F} 2$ trends $(R)$ is slightly positive (not significant as shown in the lower part of Table 1), the median of the $f o \mathrm{~F} 2$ trends(F10.7) is negative and significantly different from zero. A similar result was also obtained from the mean values of the individual trends as to be seen in the lower part of Table 1. Therefore, we observe qualitatively comparable results as for the $h m \mathrm{~F} 2$ trends reported above.

The global mean $f o \mathrm{~F} 2$ trends are shown in Fig. 7. Also here the $f o \mathrm{~F} 2 \operatorname{trend}(R)$ is slightly positive, but not significantly different from zero. The global $f \circ \mathrm{F} 2$ trend(F10.7), however, is significantly negative (for details see Table 1).

\subsubsection{Trends by use of the solar EUV proxy E10.7}

In trend analyses of selected ionospheric data series, we normally detected very similar results if we used F10.7 or E10.7 data. However, we got different results for the years 1957 and 1958. In the upper part of Fig. 8, the long-term variations of yearly averaged F10.7 (dots) and E10.7 data (crosses) are presented. The ordinate of the E10.7 data set is slightly shifted to get nearly the same level for both indices at solar minimum conditions. There is in general a satisfying agreement between both data series. Only for the years 1957-1958 the E10.7 data are markedly more enhanced than the corresponding F10.7 data. This behaviour is more clearly seen in the monthly variation shown in the lower part of Fig. 8. Especially during the months September 1957 until January 1958, the E10.7 data are markedly more strongly than the corresponding F10.7 data.

These large E10.7 data are responsible for problems in the trend analyses as demonstrated by the trends for the station Juliusruh presented in Fig. 9. Here the trends have been derived for two different data intervals: in the left part for 1957 to 2009 , in the right part for 1959 to 2009 . In the upper part the $h m \mathrm{~F} 2$ trends are shown and in the lower part the foF2 trends. The trend analyses have been carried out for both solar indices (F10.7 marked by dots, E10.7 marked by crosses). The $h m \mathrm{~F} 2$ trends (see upper part of Fig. 9) agree in nearly all cases; only the $h m \mathrm{~F} 2$ trend(E10.7) for the full data interval between 1957 and 2009 is reduced due to the extremely high E10.7 value during the year 1957. A similar behaviour can also be seen in the $f o \mathrm{~F} 2$ trends in the lower part of Fig. 9 . Here also the strong E10.7 data in 1957 and 1958 markedly influence the $f o \mathrm{~F} 2$ trend(E10.7). Due to the large E10.7 data in 1957 and 1958, the solar-induced parts are too strong and create too low $\Delta h m \mathrm{~F} 2-$ and $\Delta f o \mathrm{~F} 2$ values, and therefore the negative trends become less negative. Whereas trend 

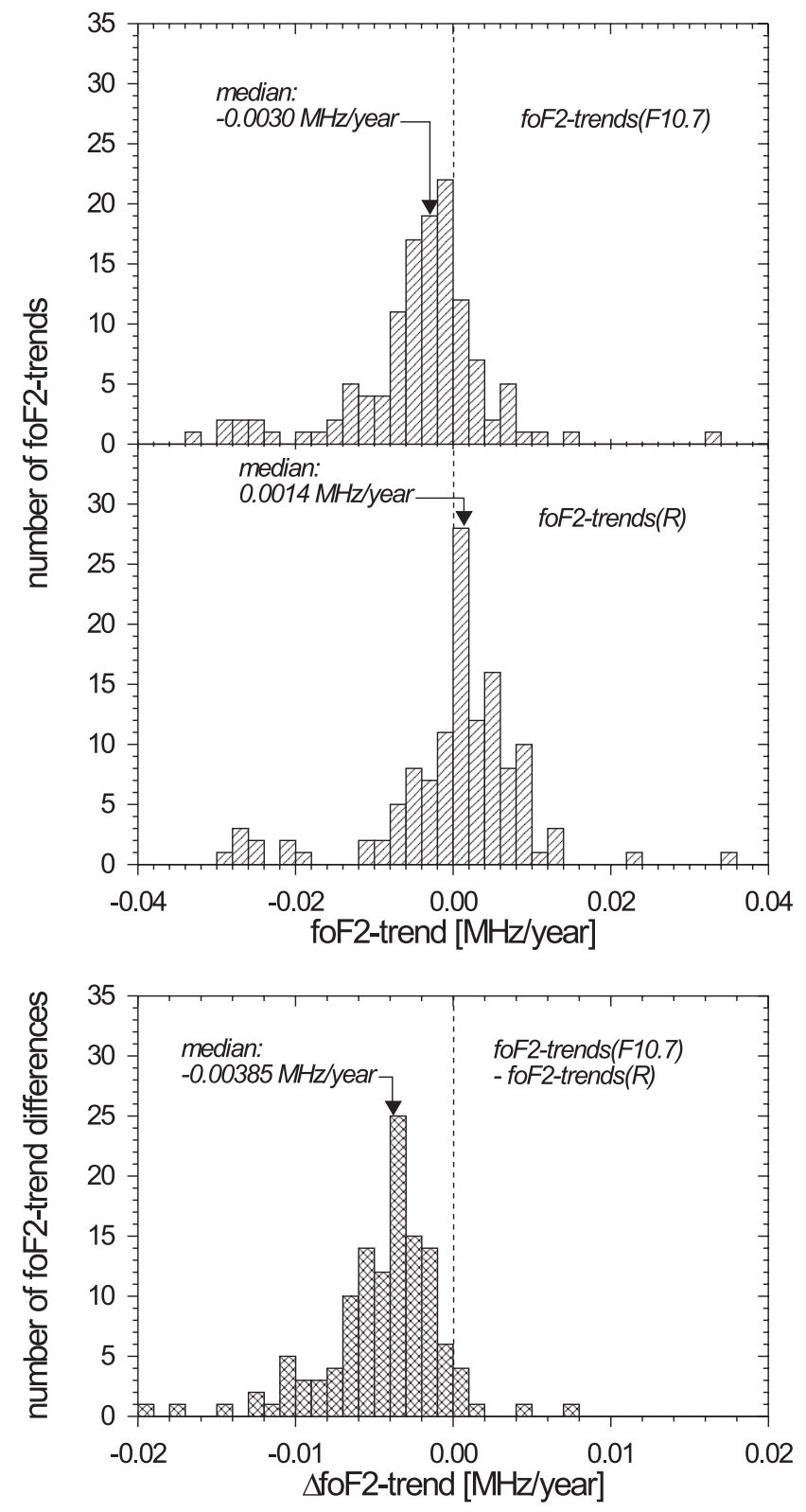

Fig. 6. Histograms of $f o \mathrm{~F} 2$ trends by use of $\mathrm{F} 10.7$ or $R$ data in the trend analyses (upper part) as well as a histogram of the differences of both $f o \mathrm{~F} 2$ trends (lower part). The corresponding median values are marked by arrows.

analyses with E10.7 data are carried out without the years 1957 and 1958, the results are in agreement with the corresponding trends using F10.7 data. Another phenomenon has to be remarked. The $\Delta f o \mathrm{~F} 2(\mathrm{E} 10.7)$ data show a stronger 11yearly variability than the corresponding $\Delta f o \mathrm{~F} 2(\mathrm{~F} 10.7)$ data, thus suggesting that the solar cycle has only partly been eliminated. In the $\Delta h m \mathrm{~F} 2(\mathrm{E} 10.7)$ data, this 11-yearly variability is smaller but can also be observed. Altogether, we conclude that ionospheric trend analyses with F10.7 data give more reliable results than the analyses with E10.7 data.

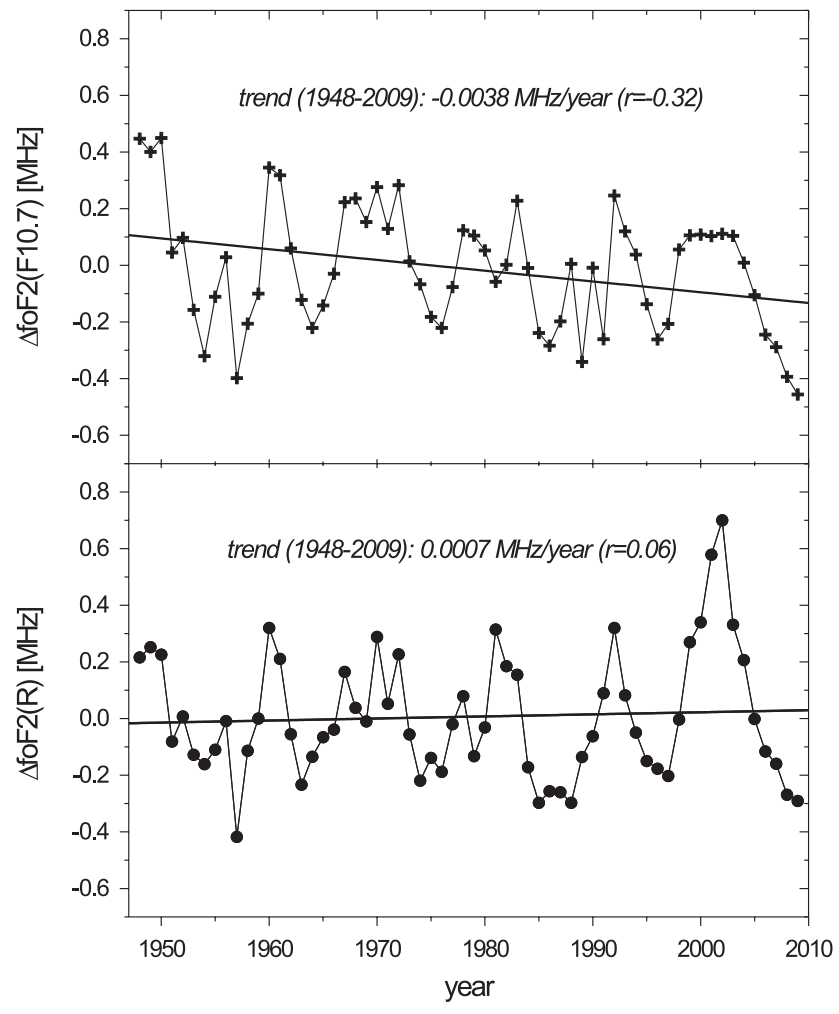

Fig. 7. Global mean $f o \mathrm{~F} 2$ trends by use of F10.7 (upper part) or $R$ data (lower part) in the trend analyses.

\subsection{Trends in dependence on data length}

Up to now we presented only trends from the interval between 1948 and 2009. In the following we will investigate trends for data intervals with different lengths. In these analyses we use only F10.7 data for the elimination of the solar activity-induced parts.

At first we estimate $h m \mathrm{~F} 2$ trends for constant interval length of 22 years continuously shifted by one year from the yearly $\Delta h m \mathrm{~F} 2$ data shown in the upper part of Fig. 5. In the upper part of Fig. 10, such $h m \mathrm{~F} 2$ trends are presented together with their error limits. The trends (marked by full dots) have been drawn for the last year of the 22-yr interval (i.e. the analysed interval started 21 years before). Whereas the $h m \mathrm{~F} 2$ trends before about 1979 are significantly negative, the trends become positive between about 1980 and 1996 (significant only between about 1983 and 1988) and become again negative after about 1997 (significant from about 2000 to the final year 2009).

In a second step we analyse the $h m \mathrm{~F} 2$ trends for different data lengths from the yearly $\Delta h m \mathrm{~F} 2$ data shown in the upper part of Fig. 5. In the lower part of Fig. 10, the trend results are presented for intervals with a fixed starting date 1948 until the last year (lower abscissa). All presented $h m \mathrm{~F} 2$ trends are significantly negative. The error bars decrease with 

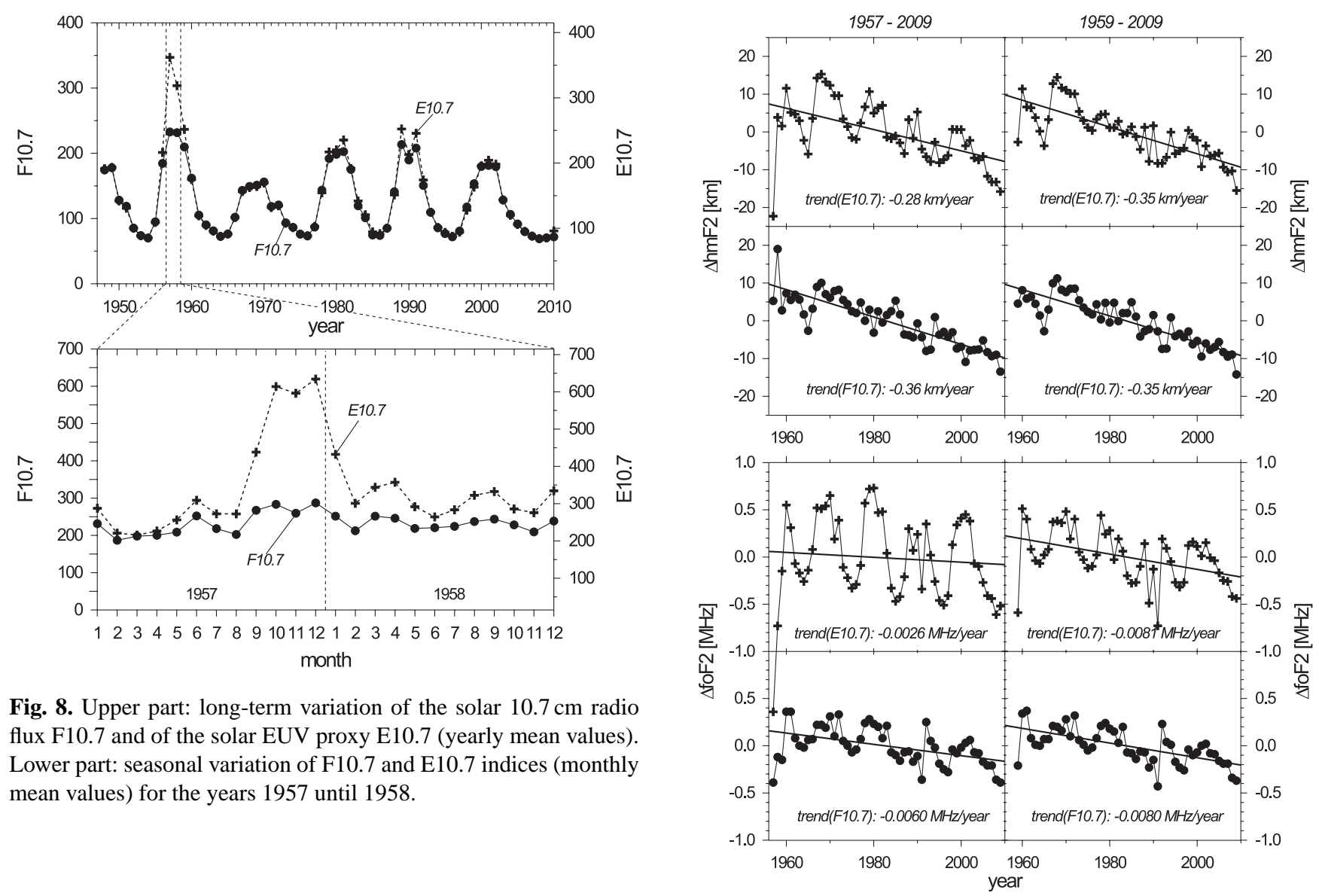

increasing length of the investigated time interval due to the increasing number of years $N$ in the denominator of Eq. (5).

The same trend analyses as for $h m \mathrm{~F} 2$ presented in Fig. 10 have also been made for $f o \mathrm{~F} 2$ trends shown in Fig. 11. These trends were estimated from the yearly $\Delta f o \mathrm{~F} 2$ data shown in the upper part of Fig. 7. The $f o \mathrm{~F} 2$ trends for intervals with a constant data length of 22 years (upper part of Fig. 11) show wave-like variations with positive and negative trend values; only some of them are significantly different from zero.

The $f o \mathrm{~F} 2$ trends for different data lengths in the lower part of Fig. 11 are nearly all negative. Whereas the significance level of the global trends before about 1988 is markedly smaller than $95 \%$, after 1990 the significance becomes better with values near about $95 \%$. This phenomenon is markedly caused by the fact that the error limit becomes smaller due to an increasing number of years $N$ in the trend analyses.

\subsection{Ionospheric changes during solar minimum 2007-2009}

In the upper part of Fig. 5, the $\Delta h m \mathrm{~F} 2$ values are markedly reduced during the solar minimum years 2007-2009, which have never been observed during the previous solar minima. A similar reduction can also be observed in $\Delta f o \mathrm{~F} 2$ values in the upper part of Fig. 7. However, this lowering of the $\Delta f o \mathrm{~F} 2$ values is not as strong as in the $\Delta h m \mathrm{~F} 2$ values.

Fig. 9. Long-term trends from ionosonde observations at Juliusruh for two different data intervals (left column: 1957-2009, right column: 1959-2009). In the upper part $h m \mathrm{~F} 2$ data are shown, in the lower part $f o \mathrm{~F} 2$ data. Solar indices used: F10.7 (dots) and E10.7 (crosses).

The special behaviour of the $\Delta h m \mathrm{~F} 2-$ and $\Delta f o \mathrm{~F} 2$ values during the solar cycle 23/24 minimum can be demonstrated by a superimposed epoch analysis. Here the solar minima (1954, 1964, 1976, 1986, 1996; shown by vertical dashed lines in Fig. 2) are used as key year zero. The parameters $\Delta h m \mathrm{~F} 2, \Delta f o \mathrm{~F} 2, \mathrm{~F} 10.7$, and Ap are separately averaged for the years -5 until +5 to get mean reference values. For each year also the corresponding error limits according to Eq. (6) have been calculated. $N$ is here, however, the number of years. These reference values (dots with error bars) are presented in Fig. 12 together with the actual values of the years 2003 until 2009 (marked by crosses). The year 2008 is the key year zero, as the minimum of the yearly $R$ and F10.7 mean values is observed here. In the paper by Bremer et al. (2012), the year 2009 has been used as key year zero in a smaller superimposed epoch analysis limited to $\Delta h m \mathrm{~F} 2$ values only. For the main results this choice is, however, unimportant. From Fig. 12 it can be seen that the $\Delta h m \mathrm{~F} 2$ values during the years 2008 and 2009 are about $12-13 \mathrm{~km}$ lower 

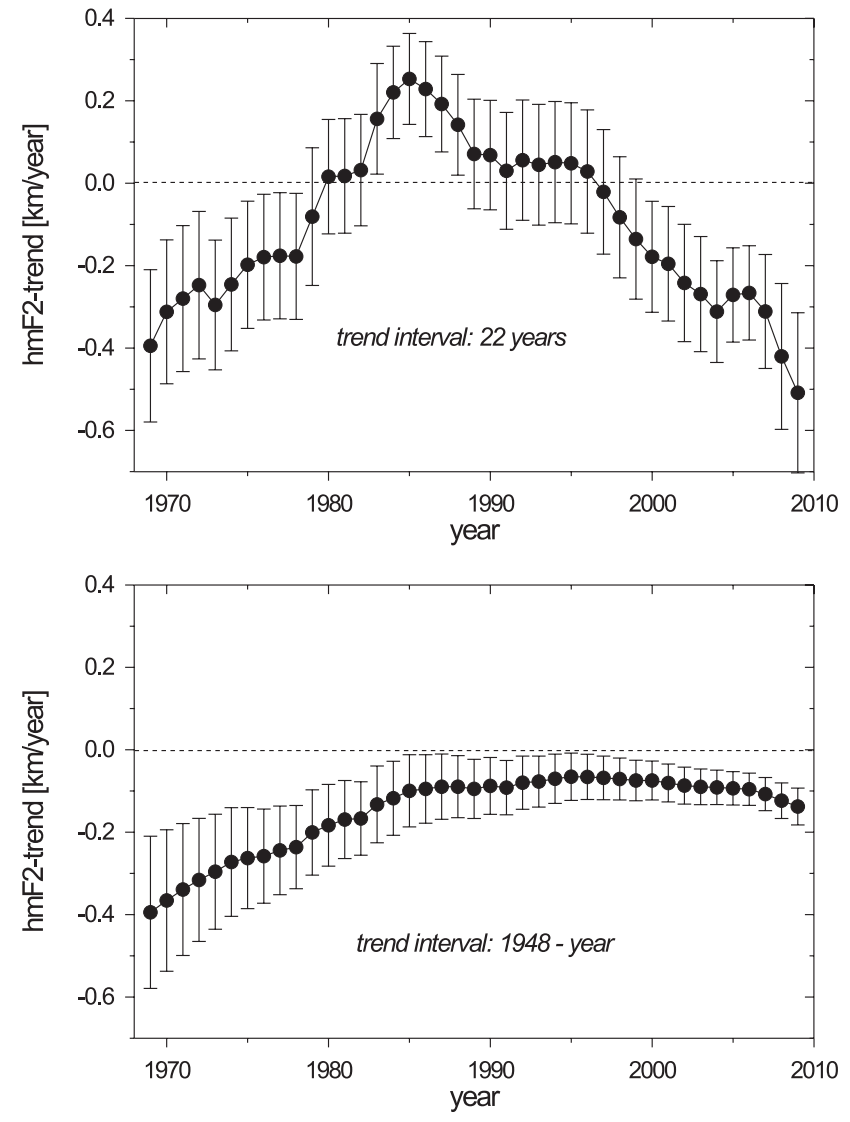

Fig. 10. Global mean $h m \mathrm{~F} 2$ trends with error bars for constant intervals of 22 years continuously shifted by one year (upper part) and for intervals with increasing data length (lower part). The trend values are drawn in both cases at the upper end of the intervals investigated.

than the corresponding reference values. For $\Delta f o \mathrm{~F} 2$ the decrease is by about $0.2 \mathrm{MHz}$ also significantly different from zero but not so pronounced in comparison with the $\Delta h m \mathrm{~F} 2$ deviations. Also the solar and especially the geomagnetic indices (F10.7 and Ap) are significantly smaller during the years of the solar minimum at the end of the solar cycle 23 and the beginning of the cycle 24 .

\section{Discussion}

Long-lasting ionosonde observations at worldwide distributed stations are very important for the derivation of trends in the ionospheric F2 region. Especially the new data collection with monthly median values of $\mathrm{M}(3000) \mathrm{F} 2$ and $f o$ F2 by Damboldt and Suessmann (2012a) is very helpful for such investigations. Nevertheless, a lot of open questions have to be solved to understand the physical background of the derived trends. Some of them will be discussed in the following subsections.
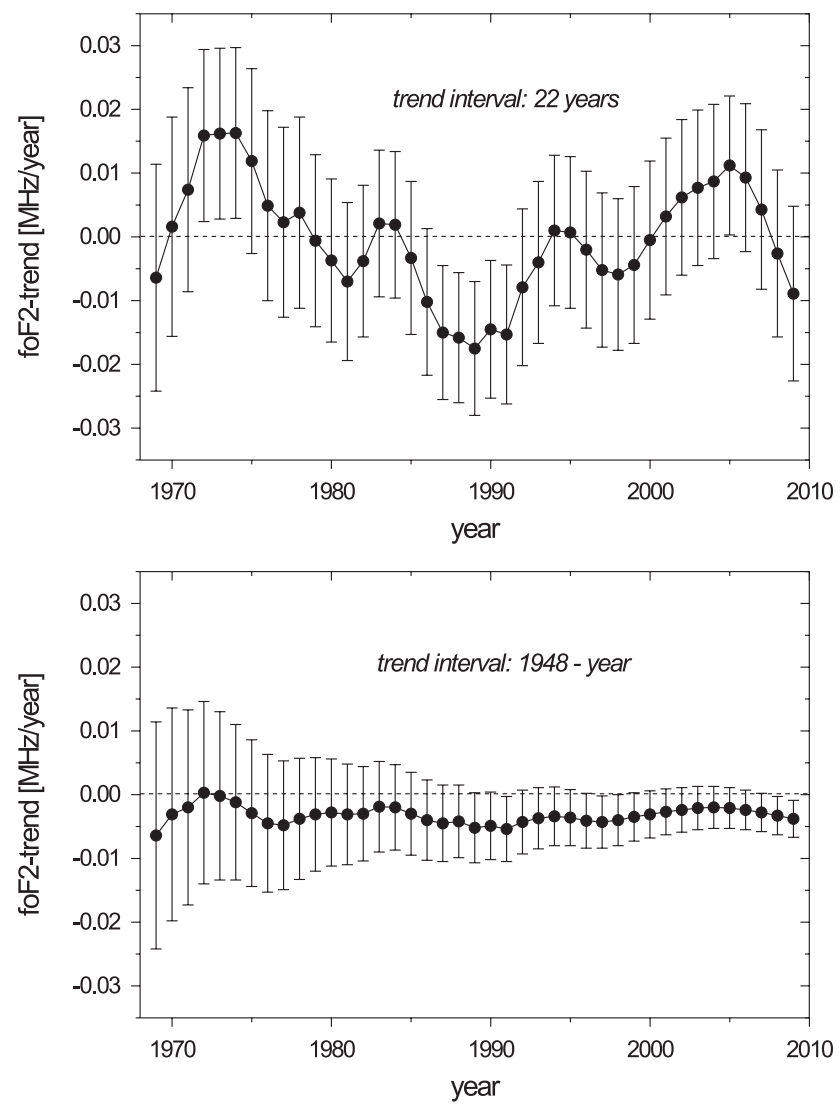

Fig. 11. Global mean $f o \mathrm{~F} 2$ trends with error bars for constant intervals of 22 years continuously shifted by one year (upper part) and for intervals with increasing data length (lower part). The trend values are drawn in both cases at the upper end of the intervals investigated.

\subsection{Solar activity indices}

As shown by Floyd et al. (2005) and Lukianova and Mursula (2011), the solar sunspot number $R$ underestimates the solar EUV flux during the years between 2001 and 2009. This phenomenon can also be confirmed by the comparison between $R$ and F10.7 in Fig. 3. Multiscale comparisons between F10.7, $R$, MGII and SOHO/SEMEUV flux by Wintoft (2011) concluded that F10.7 is the best solar EUV proxy for investigations with long time scales ( $>1.4$ years). Also in comparisons of $f o \mathrm{~F} 2$ trend analyses with different methods (Lastovicka et al., 2006), it was proposed that F10.7 may be a better solar index than the solar sunspot number $R$ for trend analyses. This statement was also confirmed by trend analyses of Jarvis et al. (1998) and Ulich et al. (2006), who found a smaller variance if F10.7 values were used instead of $R$. Therefore, it can be concluded that F10.7 data should be preferred in long-term trend analyses. The only disadvantage is that the F10.7 data series starts only in 14 February 1947. For investigations of longer data series therefore solar sunspot numbers have to be used. 
As shown in detail in Figs. 4 and 5 for $h m \mathrm{~F} 2$ trends and in Figs. 6 and 7 for $f o F 2$ trends, the use of F10.7 instead of $R$ data will make the trend values more strongly negative. The correlation coefficients between individual trends derived with $R$ and F10.7 are, however, strongly significant with $r=0.99$ for both $h m \mathrm{~F} 2$ data sets and $r=0.91$ for both $f o F 2$ data sets (not shown here). Nevertheless, the differences between the data sets can clearly be seen (e.g. in the lower parts of Figs. 4 and 6).

As shown in Figs. 8 and 9, the use of the solar EUV proxy E10.7 is only reasonable if the years 1957 and 1958 are excluded in the trend analyses. In conclusion we prefer the use of F10.7 data for time intervals starting after 1948 (more exact after 14 February 1947).

\subsection{Length of data interval}

At the beginning of our trend analyses, we believed in agreement with Lastovicka et al. (2006) that in trend analyses with data length of about 22 years the influence of the solar cycle can satisfyingly be removed. The global $f o \mathrm{~F} 2$ trends with constant length (upper part of Fig. 11) show, however, variations with a nearly 11-yearly period and small indications of a trend variation with a longer period.

Also in the $h m \mathrm{~F} 2$ trends (upper part of Fig. 10) periodical variations can be seen. Here, however, the long-term variation is more pronounced with negative values at the beginning and the end of the analysed time interval and positive values in the middle of the investigated interval. A nearly 11yearly trend variation is markedly smaller but can also partly be detected.

The reason for the periodical 11-yearly variations in the $f o \mathrm{~F} 2$ - and $h m \mathrm{~F} 2$ trends is probably caused by the 11-yearly solar cycle which could not totally be removed in the trend analyses of the 22-yearly intervals. The reason for the longer trend variation (most markedly detected in the $h m \mathrm{~F} 2$ trends, but also to be seen in the $f o \mathrm{~F} 2$ trends) is still unclear and requires further investigations.

The trends for increasing data intervals of the analysed data sets in the lower parts of Figs. 10 and 11 show more stable variations and suggest that the derived mean $h m \mathrm{~F} 2$ and $f o \mathrm{~F} 2$ trends are more reliable for longer data intervals as the error bars become smaller with increasing number $N$ of years. Therefore, for tests of an increasing atmospheric greenhouse effect (see Sect. 4.5 below), ionospheric data series of about 50-60 year duration are necessary to get significant long-term trend results. This result is in general agreement with Jarvis et al. (2002).

\subsection{Solar activity minimum 2007-2009}

As shown in Fig. 12 the observed $\Delta h m \mathrm{~F} 2$ values are during the solar cycle 23/24 minimum up to about $13 \mathrm{~km}$ lower than the corresponding reference values deduced from the

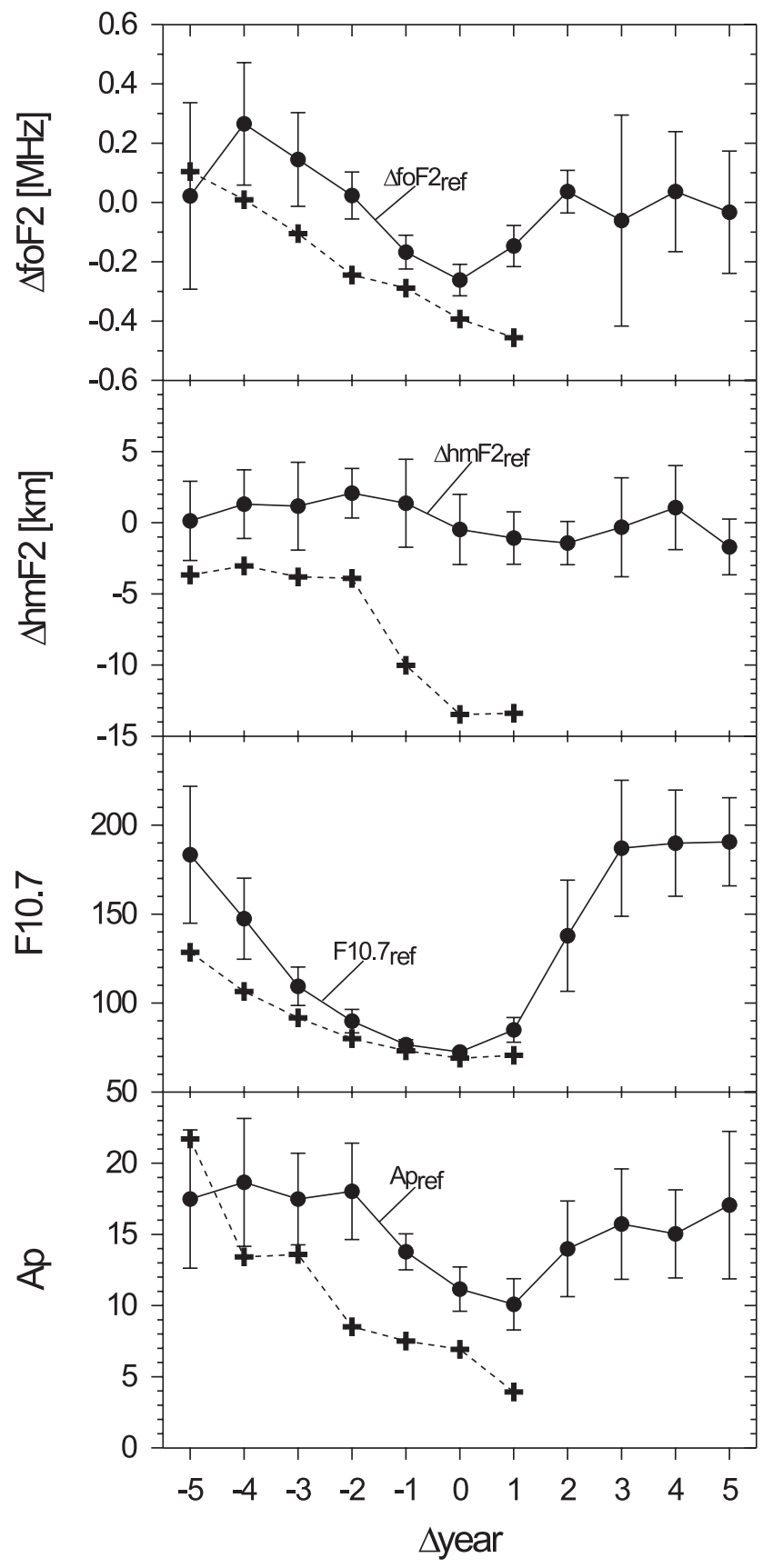

Fig. 12. Comparison of global yearly mean values of $\Delta f o \mathrm{~F} 2$, $\Delta h m \mathrm{~F} 2, \mathrm{~F} 10.7$, and Ap values from the years 2003 until 2009 (crosses connected with dashed lines) with corresponding reference values derived by a superimposed epoch analysis from the previous solar minima (full dots with error bars connected with continuous lines).

preceding solar minima. Also the $\Delta f o \mathrm{~F} 2$ values are about 0.1 to $0.3 \mathrm{MHz}$ smaller than the estimated reference values.

A similar unusual behaviour of the upper atmosphere has been reported by Emmert et al. (2010) in the thermospheric density derived by satellite drag observations. These authors 


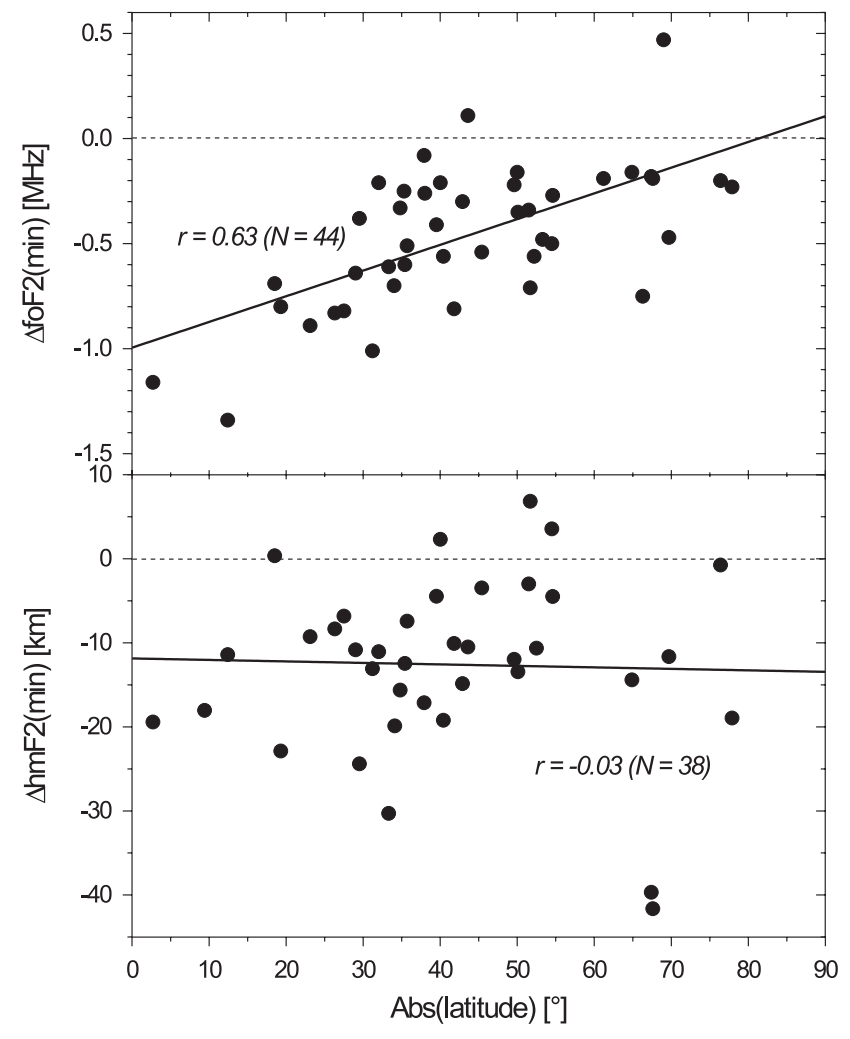

Fig. 13. Minimum values of $\Delta f o \mathrm{~F} 2$ and $\Delta h m \mathrm{~F} 2$ from the years 2007-2009 in dependence on the absolute values of the latitude of the investigated stations $(N$ : number of stations, $r$ : correlation coefficient).

detected density reductions up to $-30 \%$ during the solar cycle 23/24 minimum. The reason for this effect is not conclusively resolved. According to Solomon et al. (2010), the unusually low EUV irradiances during the solar minimum of the solar 23/24 cycle may play an essential role.

The extreme lowering of the $\Delta h m \mathrm{~F} 2$ values is strongly connected with the observed thermospheric density reduction. Due to typical density profiles of the COSPAR International Reference Atmosphere (CIRA, 1972), a density reduction by about $30 \%$ corresponds to a height lowering of about $7-10 \mathrm{~km}$. The abovementioned ionospheric effect with about $13 \mathrm{~km}$ is markedly stronger. The ionospheric effect is probably caused by the lowering of the atmospheric density together with a markedly reduced ionization due to the extremely low solar radiation as well as geomagnetic activity (see corresponding F10.7 and Ap curves in Fig. 12). The reduced $\Delta f o \mathrm{~F} 2$ values during the solar cycle $23 / 24$ minimum could also be caused by the extremely low solar and geomagnetic activity. Such reduced $f o \mathrm{~F} 2$ and $h m \mathrm{~F} 2$ values at low solar activity conditions can be expected due to the well-known positive correlation between these parameters and the solar activity (corresponding figures can be seen in Hargreaves, 1979, and Bremer, 2001).
For an investigation of this unusual ionospheric effect during the solar cycle 23/24 minimum in dependence on latitude, we estimated for each station the $h m \mathrm{~F} 2-$ and $f o \mathrm{~F} 2$ trends from the data between 1948 and 2006. With these linear equations we calculated the theoretical values for the years 2007, 2008 and 2009 and estimated the differences to the corresponding experimental values of these three years. From these three difference values, we estimated the minimum value $\Delta h m \mathrm{~F} 2(\mathrm{~min})$ and $\Delta f o \mathrm{~F} 2(\mathrm{~min})$ for each station. In Fig. 13 these values are shown in dependence on latitude (more correct: on the absolute value of the latitude. Due to the limited number of values $N$, the min-data of both hemispheres are not separately presented). The $\Delta h m \mathrm{~F} 2(\mathrm{~min})$ values are nearly independent of latitude. The mean $\Delta h m \mathrm{~F} 2(\mathrm{~min})$ value at the pole with about $-13 \mathrm{~km}$ is only slightly lower than at the Equator with about $-12 \mathrm{~km}$. This difference is statistically insignificant. In contrast to the $\Delta h m \mathrm{~F} 2(\mathrm{~min})$ values, the $\Delta f o \mathrm{~F} 2(\mathrm{~min})$ values strongly depend on the latitude as shown in the upper part of Fig. 13. Whereas the mean $\Delta f o \mathrm{~F} 2(\mathrm{~min})$ value at the pole is nearly zero, at the Equator the mean $\Delta f o \mathrm{~F} 2(\mathrm{~min})$ value is about $-1.0 \mathrm{MHz}$. Due to the smaller solar zenith angle at the Equator, the reduced EUV irradiation is more effective there and causes a stronger decrease of the $\Delta f o \mathrm{~F} 2(\mathrm{~min})$ values than at the pole. As easily shown by the statistical Student's $t$ test (Taubenheim, 1969), the dependence of the $\Delta f o \mathrm{~F} 2(\mathrm{~min})$ values on the absolute values of the latitude is strongly significant. The dependence of $\Delta h m \mathrm{~F} 2(\mathrm{~min})$ - and $\Delta f o \mathrm{~F} 2(\mathrm{~min})$ values on geomagnetic latitude (not shown here) is nearly identical with the results shown in Fig. 13.

\subsection{Comparison with other trend analyses}

Damboldt and Suessmann (2012b) recently estimated also global $h m \mathrm{~F} 2-$ and $f o \mathrm{~F} 2$ trends with data of the same databank (Damboldt and Suessmann, 2012a) as used in this paper. However, these authors utilised another analysis method. They eliminated the solar cycle influence by means of a CCIR ionospheric prediction model (ITU, 2009). Nevertheless the results of both data analyses agree quite reasonably with global negative $h m \mathrm{~F} 2$ - and positive $f o \mathrm{~F} 2$ trends, however, only if the solar sunspot number $R$ is used in both data analyses (in agreement with investigations of Bremer et al. (2012) with a markedly smaller data volume). Using, however, F10.7 values in the data analyses presented in this paper, the global trends of $h m \mathrm{~F} 2$ and $f o \mathrm{~F} 2$ are both negative (see upper parts of Figs. 5 and 7) and agree with model results as shown in the next Sect. 4.5. Unfortunately, the CCIR model can only be run with $R$ but not with F10.7 data.

As shown in the upper parts of Figs. 10 and 11, the trends deduced from shorter time intervals (here 22 years) demonstrate with periodical variations marked deviations from the global mean trends estimated from the full data interval. Deviations from the mean trends have also been found by Damboldt and Suessmann (2012b) if they estimated $h m \mathrm{~F} 2$ 
Table 2. Estimated mean trend values of $h m \mathrm{~F} 2$ and $f o \mathrm{~F} 2$ with error bars using F10.7 data as solar activity index in the trend analyses of 113 stations with $h m \mathrm{~F} 2$ values and 124 stations with $f o \mathrm{~F} 2$ data for two different time intervals (1948-2009 and 1948-2006).

\begin{tabular}{llll}
\hline Parameter & Trend type & Trend (1948-2009) & Trend (1948-2006) \\
& Global trend & -0.138 & -0.096 \\
& & $\pm 0.045 \mathrm{~km} \mathrm{year}^{-1}$ & $\pm 0.039 \mathrm{~km} \mathrm{year}^{-1}$ \\
& Individual trends (mean) & -0.121 & -0.088 \\
& & $\pm 0.088 \mathrm{~km} \mathrm{year}^{-1}$ & $\pm 0.089 \mathrm{~km} \mathrm{year}^{-1}$ \\
& Individual trends (median) & $-0.114 \mathrm{~km} \mathrm{year}^{-1}$ & $-0.072 \mathrm{~km} \mathrm{year}^{-1}$ \\
\hline \multirow{3}{*}{ foF2 } & Global trend & -0.0038 & -0.0024 \\
& & $\pm 0.0029 \mathrm{MHz} \mathrm{year}^{-1}$ & $\pm 0.0031 \mathrm{MHz} \mathrm{year}^{-1}$ \\
& Individual trends (mean) & -0.0042 & -0.0032 \\
& & $\pm 0.0016 \mathrm{MHz} \mathrm{year}^{-1}$ & $\pm 0.0017 \mathrm{MHz} \mathrm{year}^{-1}$ \\
& Individual trends (median) & $-0.0030 \mathrm{MHz} \mathrm{year}^{-1}$ & $-0.0022 \mathrm{MHz} \mathrm{year}^{-1}$ \\
\hline
\end{tabular}

trends before and after 1964 (negative trend before 1964 and positive trend after this year). This behaviour can also be seen in the lower part of Fig. 5 where $R$ is used as solar activity index. If F10.7 is used in the trend analyses, more detailed trend variations were found as can be seen in the upper parts of Figs. 10 and 11.

It can be concluded that both methods reasonably agree only if $R$ values are used. As mentioned above differences occur, however, if different solar activity indices are used, in the CCIR method $R$ values and in our regression analysis F10.7 data. Some additional differences may result from the fact that the influence of geomagnetic activity is not included in the CCIR method. Also the investigated data volumes are slightly different. Whereas in this paper only data series with more than 22 years have been analysed, in the paper of Damboldt and Suessmann (2012b) all available stations are included even if the data series are very short.

\subsection{Comparison with model results}

As remarked in Sect. 4.3, the years 2007 until 2009 show an anomalous behaviour which is not caused by long-term variations in the Earth's atmosphere/ionosphere. Therefore, these years will be excluded from investigations of long-term trends and their comparison with long-term model results. In Table 2 the corresponding $h m \mathrm{~F} 2-$ and $f o \mathrm{~F} 2$ trends are shown for the time interval from 1948 until 2009 as well as for the interval from 1948 until 2006. As to be expected from the trend results shown in the upper parts from Figs. 5 and 7, the trends without the years 2007-2009 are not so strongly negative compared to the trends that include these three years. Also the significance levels of the trends (1948-2006) are smaller than those for the trends (1948-2009). Nevertheless for some trends (1948-2006) the significance level is more than $95 \%$ (global $h m \mathrm{~F} 2$ trend, individual mean $f_{o} \mathrm{~F} 2$ trend), for the individual mean $h m \mathrm{~F} 2$ trend slightly below $95 \%$ and for the global $f o \mathrm{~F} 2$ trend about $87 \%$.
According to an excellent review paper by Qian et al. (2011), there are different theories to explain the ionospheric trends in the F2 region: a cooling of the atmosphere by an increasing greenhouse effect (Rishbeth and Roble, 1992; Qian et al., 2009); long-term changes of the Earth's magnetic field (Cnossen and Richmont, 2008); changes of the geomagnetic activity (Mikhailov, 2002); and the influence of non-migrating tides (Bencze, 2009).

If we expect that the mean $h m \mathrm{~F} 2-$ and $f o \mathrm{~F} 2$ trends are caused by an increasing greenhouse effect, we have to compare the mean trend values in the right column of Table 2 with available model results. Unfortunately, the model results are normally carried out for a doubling of the atmospheric greenhouse gases. Therefore, we have to extrapolate our trend values to an interval corresponding to such a doubling of the greenhouse gases. According to Houghton et al. (2001) and Brasseur and de Rudder (1987), the content of the atmospheric greenhouse gases increased about $20 \%$ during 40 years. Assuming a linear relationship between the amount of the greenhouse gases and the ionospheric effect, then for the doubling of the greenhouse gases the experimental trends have to be multiplied by 200 to get the ionospheric effect which can be compared with the model values. In Table 3 there are presented the experimental trends (Exp. trends, derived from the right column of Table 2), the extrapolated experimental changes (Exp. $2 \mathrm{xCO}_{2}$ effect), and the model values from Rishbeth and Roble (1992) (Th. $2 \mathrm{xCO}_{2}$ effect). The agreement between the experimental effects with the model results is very reasonable. Therefore, the global long-term mean $h m \mathrm{~F} 2$ - and $f o \mathrm{~F} 2$ trends strongly confirm the importance of the atmospheric greenhouse effect. This agreement could, however, only be achieved if F10.7 data are used in the trend analyses. The mean $f o \mathrm{~F} 2(R)$ trends, however, are slightly positive (see Table 1) and disagree with the model predictions. Qualitatively, the same result was also detected by trend analyses in dependence on $R$ with a reduced data volume (Bremer et al., 2012). 
Table 3. Collection of experimental trends from the right column of Table 2, extrapolated experimental effects for $\mathrm{CO}_{2}$ doubling, and model results for doubling of the $\mathrm{CO}_{2}$. For details see text.

\begin{tabular}{llll}
\hline Parameter & Exp. trends & Exp. 2xCO $\mathrm{CO}_{2}$ effect & Th. 2xCO $\mathrm{CO}_{2}$ effect \\
\hline$h m \mathrm{~F} 2$ & $-0.07 \ldots-0.10 \mathrm{~km} \mathrm{year}^{-1}$ & $-14 \ldots-20 \mathrm{~km}$ & $-10 \ldots-20 \mathrm{~km}$ \\
$f o \mathrm{~F} 2$ & $-0.002 \ldots-0.003 \mathrm{MHz}_{\mathrm{year}}^{-1}$ & $-0.4 \ldots-0.6 \mathrm{MHz}$ & $-0.2 \ldots-0.5 \mathrm{MHz}$ \\
\hline
\end{tabular}

As remarked above (see upper parts of Figs. 10 and 11 and comments in Sect. 4.2) in trends with shorter data series, variations can be detected which cannot be explained by an increasing atmospheric greenhouse effect.

\section{Conclusions}

The presented results of trends in the ionospheric F2 region are based on a recently available data collection by Damboldt and Suessmann (2012a). From this databank with monthly median values of $f_{o} \mathrm{~F} 2$ and $\mathrm{M}(3000) \mathrm{F} 2$, trend analyses with a twofold regression method have been carried out for 113 different stations with $h m \mathrm{~F} 2$ data (derived from M(3000)F2 values) and for 124 stations with foF 2 data. The following main results were obtained:

- The elimination of the solar-induced variations can preferably be made with the solar $10.7 \mathrm{~cm}$ radio flux. Especially during the years from 2001 until 2009, the relative solar sunspot number $R$ markedly underestimated the solar EUV flux. The E10.7 data are in general very similar to the F10.7 data. However, the E10.7 values during the solar maximum years 1957 and 1958 are strongly enhanced and cause erroneous trend estimations. The trends derived by means of the solar $10.7 \mathrm{~cm}$ radio flux give the most reliable ionospheric trend results. Therefore, we recommend the use of the F10.7 index in atmospheric/ionospheric trend analyses.

- Global mean $h m \mathrm{~F} 2$ - and $f o \mathrm{~F} 2$ trends derived from the time interval between 1948 and 2006 are significantly different from zero with reliability from about $87 \%$ up to a level greater than $95 \%$. These trends are in surprisingly reasonable agreement with model results, thus demonstrating that long-term variations in the atmosphere/ionosphere can be explained by the atmospheric greenhouse effect.

- During the solar cycle 23/24 minimum (years 20072009), a marked lowering was detected of $h m \mathrm{~F} 2$ up to $13 \mathrm{~km}$ and of foF 2 up to about $0.3 \mathrm{MHz}$ compared with previous solar activity minima conditions. This phenomenon is mainly caused by a thermospheric density reduction detected in satellite drag observations by Emmert et al. (2010) together with a reduced ionization due to extremely low solar and geomagnetic activities.
In the present paper the investigations have mainly been restricted to the derivation of global mean trends. Regional differences of the $h m \mathrm{~F} 2-$ and foF 2 trends will be discussed in a planned paper in near future.

Acknowledgements. The authors thank W. Kent Tobiska and Justin Bailey for sending daily E10.7 values from the Solar Irradiance Platform (SIP v2.37) and Marius Zecha for technical support.

Topical Editor K. Kauristie thanks M. Jarvis and one anonymous referee for their help in evaluating this paper.

\section{References}

Alfonsi, L., de Franceschi, G., Perrone, L., and Materassi, M.: Long-term trends of the critical frequency of the F2 layer at northern and southern high latitude regions, Phys. Chem. Earth, 27, 607-612, 2002.

Bencze, P.: Geographical distribution of long-term changes in the height of the maximum electron density of the $F$ region: A nonmigrating tidal effect?, J. Geophys. Res., 114, A06304, doi:10.1029/2008JA013492, 2009.

Bilitza, D., Sheikh, N. M., and Eyfrig, R.: A global model for the height of the F2-peak using M3000 values from CCIR, Telecommunication Journal, 46, 549-553, 1979.

Brasseur, G. and de Rudder, A.: The potential impact on atmospheric ozone and temperature of increasing trace gas concentrations, J. Geophys. Res., 92, 10903-10920, 1987.

Bremer, J.: Ionospheric trends in mid-latitudes as a possible indicator of the atmospheric greenhouse effect, J. Atmos. Terr. Phys., 54, 1505-1511, 1992.

Bremer, J.: Trends in the thermosphere derived from global ionosonde observations, Adv. Space Res., 28, 997-1006, 2001.

Bremer, J.: Investigations of long-term trends in the ionosphere with world-wide ionosonde observations, Adv. Radio Sci., 2, 253258, 2004, http://www.adv-radio-sci.net/2/253/2004/.

Bremer, J., Damboldt, T., Mielich, J., and Suessmann, P.: Comparing long-term trends in the ionospheric F2-region with two different methods, J. Atmos. Solar-Terr. Phys., 77, 174-185, 2012.

CIRA: COSPAR International Reference Atmosphere, Akadenie Verlag, Berlin, 1972.

Cnossen, I. and Richmond, A. D.: Modelling the effect of changes in the Earth's magnetic field from 1957 to 1997 on the ionospheric $h m \mathrm{~F} 2$ and $f o \mathrm{~F} 2$ parameters, J. Atmos. Solar-Terr. Phys., 70, 1512-1524, doi:10.1016/j.jastp.2008.05.003, 2008.

Damboldt, T. and Suessmann, P.: Consolidated Database of worldwide measured monthly medians of ionospheric characteristics 
foF2 and M(3000)F2, INAG Bulletin on the Web, INAG-73, www.ips.gov.au/IPSHosted/INAG/web-73/index.html, 2012a.

Damboldt, T. and Suessmann, P.: Statistic of long-term ionospheric measurements, Adv. Radio Sci., 10, 255-258, 2012b, http://www.adv-radio-sci.net/10/255/2012/.

Danilov, A. D.: The method of determination of the long-term trends in the $\mathrm{F} 2$ region independent of geomagnetic activity, Ann. Geophys., 20, 511-521, doi:10.5194/angeo-20-511-2002, 2002.

Danilov, A. D.: Long-term trends of $f_{o} \mathrm{~F} 2$ independent of geomagnetic activity, Ann. Geophys., 21, 1167-1176, doi:10.5194/angeo-21-1167-2003, 2003.

de Adler, N. O., Elias, A. G., and Heredia, T.: Long-term trend in the ionospheric F2 layer peak height at a southern low latitude station, Phys. Chem. Earth, 27, 613-615, 2002.

Emmert, J. T., Jean, J. L., and Picone, J. M.: Record-low thermospheric density during the 2008 solar minimum, Geophys. Res. Lett., 37, L12102, doi:10.1029/2010GL043671, 2010.

Floyd, L., Newmark, J., Cook, J., Herring, L., and McMullin, D.: UV spectral irradiances and solar indices, J. Atmos. Solar-Terr. Phys., 67, 3-15, 2005.

Hall, C. M. and Cannon, P. S.: Trends in foF2 above Troms $\varnothing\left(69^{\circ} \mathrm{N}, 19^{\circ} \mathrm{E}\right)$, Geophys. Res. Lett., 29, 2128, doi:10.1029/2002GL016259, 2002.

Hargreaves, J. K.: The upper atmosphere and solar-terrestrial relations, Van Nostrand Reinhold Company, New York-CincinnetiToronto-London-Melbourne, 1979.

Houghton, J. T., Ding, Y., Groggs, D. J., Noguer, M., van der Linden, P. J., Dai, X., Maskell, K., and Johnson, C. A.: Climate Change: The Scientific Basis, Contribution of WG I to the 3rd Assessment Report of the IPCC, Cambridge, University Press, 2001.

ITU: Recommendation ITU-R P.1239-2, International Telecommunication Union, Geneva, 2009.

Jarvis, M. J., Jenkins, B., and Rodgers, G. A.: Southern hemisphere observations of long-term decrease in F region altitude and thermospheric wind providing possible evidence for global thermospheric cooling, J. Geophys. Res., 103, 20775-29787, 1998.

Jarvis, M. J., Clilverd, M. A., and Ulich, T.: Methodological influences on F-region peak height trend analyses, Phys. Chem. Earth, 27, 589-594, 2002.

Lastovicka, J., Mikhailov, A. V., Ulich, T., Bremer, J., Elias, A. G., Ortis de Adler, N., Jara, V., Abarca del Rio, R., Foppiano, A. P., Ovalle, E., and Danilov, A. D.: Long-term trends in foF2: A comparison of various methods, J. Atmos. Solar-Terr. Phys., 68, 1854-1870, 2006.

Lukianova, R. and Mursula, K.: Changed relation between sunspot numbers, solar UV/EUV radiation and TSI during the declining phase of solar cycle 23, J. Atmos. Solar-Terr. Phys., 73, 235-240, 2011.

Mikhailov, A. V.: The geomagnetic control concept of the F2-layer parameter long-term trends, Phys. Chem. Earth, 27, 595-606, 2002.
Mikhailov, A. V., Marin, D., Leschinskaya, T. Yu., and Herraiz, M.: A revised approach to the foF2 long-term trends analysis, Ann. Geophys., 20, 1663-1675, doi:10.5194/angeo-20-16632002, 2002.

Qian, L., Burns, A. G., Solomon, S. C., and Roble, R. G.: The effect of carbon dioxide cooling on trends in the F2-layer ionosphere, J. Atmos. Solar-Terr. Phys., 71, 1592-1601, 2009.

Qian, L., Lastovicka, J., Roble, R. G., and Solomon, S. C.: Progress in observations and simulations of global change in the upper atmosphere, J. Geophys. Res., 116, A00H03, doi:10.1029/2010JA016317, 2011.

Rishbeth, H.: A greenhouse effect in the ionosphere?, Planet. Space Sci., 38, 945-948, 1990.

Rishbeth, H. and Roble, R. G.: Cooling of the upper atmosphere by enhanced greenhouse gases - Modelling of the thermospheric and ionospheric effects, Planet. Space Sci., 40, 1011-1026, 1992.

Roble, R. G. and Dickinson, R. E.: How will changes of carbon dioxide and methane modify the mean structure of the mesosphere and thermosphere?, Geophys. Res. Lett., 16, 1441-1444, 1989.

Shimazaki, T.: World wide daily variations in the height of the maximum electron density in the ionospheric F2 layer, J. Radio Res. Labs., Japan, 2, 85-97, 1955.

Solomon, S. C., Woods, T. N., Didkovsty, L. V., Emmert, J. T., and Qian, L.: Anomalously low solar extreme-ultraviolet irradiance and thermospheric density during solar minimum, Geophys. Res. Lett., 37, L16103, doi:10.1029/2010GL044468, 2010.

Taubenheim, J.: Statistische Auswertung geophysikalischer und meteorologischer Daten, Akad. Verlagsgesellschaft Geest und Portig K.-G., Leipzig, 1969.

Tobiska, W. K., Woods, T., Eparvier, F., Viereck, R., Floyd, L., Bouwer, D., Rottmann, G., and White, O. R.: The SOLAR2000 empirical solar irradiance model and forecast tool, J. Atmos. Solar-Terr. Phys., 62, 1233-1250, 2000.

Ulich, T.: Solar variability and long-term trends in the atmosphere, Sodankylä Geophysical Observatory Publications, No. 87, Oulu, 2000.

Ulich, T., Clilverd, M. A., Jarvis, M. J., and Rishbeth, H.: Unravelling signs of global change in the ionosphere, in: Space Weather - Research towards applications in Europe, edited by: Lilensten, J., Astrophys. Space Library, 344, 95-105, Springer, Dordrecht, The Netherlands, 2006.

Wintoft, P.: The variability of solar EUV: A multiscale comparison between sunspot number, $10.7 \mathrm{~cm}$ flux, LASP MgII index, and SOHO/SEM EUV flux, J. Atmos. Solar-Terr. Phys., 73, 17081714, 2011.

Yue, X., Wan, W., Liu, L., Ning, B., and Zhao, B.: Applying artificial neural network to derive long-term $f o \mathrm{~F} 2$ trends in the Asia/Pacific sector ftom ionosonde observations, J. Geophys. Res., 111, A10303, doi:10.1029/2005JA011577, 2006. 